\title{
Real-time evaluation of optic nerve sheath diameter (ONSD) in awake neurosurgical patients
}

\author{
N Weidner ${ }^{1 *}$, H Bomberg ${ }^{1}$, S Antes ${ }^{2}$, A Meiser $^{1}$, T Volk ${ }^{1}$, HV Groesdonk \\ From ESICM LIVES 2015 \\ Berlin, Germany. 3-7 October 2015
}

\section{Introduction}

Ultrasound measurement of the optic nerve sheath diameter (ONSD) has been utilized as an indirect assessment of intracranial pressure (ICP). Currently, the normal ONSD is believed to be $<5 \mathrm{~mm}$, whereas diameters above $6 \mathrm{~mm}$ are considered to reflect a clinically significant increase in ICP. Despite these standard values, the ONSD has never been compared with simultaneously measured ICP values in awake, spontaneously breathing patients.

\section{Objectives}

In this prospective study, we investigated the correlation between ONSD and the simultaneously measured ICP by means of an intraparenchymatic P-Tel probe in awake, spontaneously breathing patients.

\section{Methods}

ICP was measured continuously in 15 patients by means of an intraparenchymatic P-Tel probe. Additionally, ONSD was measured in all patients by the readily available LOGIQ e Ultrasound machine from General Electric (GE Healthcare, Little Chalfont, UK) with a high-frequency $7.5-10-\mathrm{MHz}$ or higher linear array ultrasound transducer. The ONSD was measured $3 \mathrm{~mm}$ behind the optic disc in both transverse and sagittal planes. The average of the three measurements was recorded and compared with the ICP. Additionally, ONSD of patients with an ICP of 1-10 $\mathrm{mmHg}(\mathrm{n}=6)$ were compared with ONSD of patients suffering from an ICP of 11-20 $\mathrm{mmHg}(\mathrm{n}=9)$.

\section{Results}

In all patients and for both eyes, the ONSD correlated well with the simultaneously measured ICP (Pearson $\mathrm{R}=0.77-\mathrm{R}=0.88$ ). Comparison of patients with

\footnotetext{
${ }^{1}$ University Hospital Homburg/Saar, Department of Anesthesiology, Critical Care and Pain Medicine, Homburg, Germany

Full list of author information is available at the end of the article
}

normal and increased ICP revealed that the ONSD measurement accurately predicts an elevated ICP with an optimal cut-off value of $5.05 \mathrm{~mm}$ (AUC of 0.93 , sensitivity $92 \%$, and specificity $89 \%, \mathrm{p}<0.001)$.

\section{Conclusions}

This study underlines the usefulness of ONSD measurement to accurately predict increased ICP, especially in awake, spontaneously breathing patients.

\section{Authors' details}

${ }^{1}$ University Hospital Homburg/Saar, Department of Anesthesiology, Critical Care and Pain Medicine, Homburg, Germany. ${ }^{2}$ University Hospital Homburg/ Saar, Department of Neurosurgery, Homburg, Germany.

Published: 1 October 2015

doi:10.1186/2197-425X-3-S1-A608

Cite this article as: Weidner et al:: Real-time evaluation of optic nerve sheath diameter (ONSD) in awake neurosurgical patients. Intensive Care Medicine Experimental 2015 3(Suppl 1):A608.

Submit your manuscript to a SpringerOpen ${ }^{\bullet}$ journal and benefit from:

- Convenient online submission

- Rigorous peer review

- Immediate publication on acceptance

- Open access: articles freely available online

- High visibility within the field

- Retaining the copyright to your article

Submit your next manuscript at $>$ springeropen.com (c) 2015 Weidner et al.; This is an Open Access article distributed under the terms of the Creative Commons Attribution License (http:// creativecommons.org/licenses/by/4.0), which permits unrestricted use, distribution, and reproduction in any medium, provided the original work is properly cited. 